\title{
Coronavirus stress and COVID-19 burnout among healthcare staffs: The mediating role of optimism and social connectedness
}

\author{
Murat Yıldırım $^{1,2}$ (D) IIIhan Çiçek ${ }^{3}$. Mehmet Emin Şanlı ${ }^{4}$ \\ Accepted: 21 April 2021 / Published online: 23 April 2021 \\ (C) The Author(s), under exclusive licence to Springer Science+Business Media, LLC, part of Springer Nature 2021
}

\begin{abstract}
Coronavirus stress has been associated with undesirable mental health and well-being outcomes, including burnout. However, little is known about the underlying mechanism of change. The present study aimed to examine if optimism and social connectedness mediated the relationship between coronavirus stress and COVID-19 burnout in a large sample of healthcare staffs. Participants included 1046 healthcare staffs $(56.8 \%$ females) aged 20-61 years (mean age $=30.29$ years, $\mathrm{SD}=7.80$ ), who completed the measures of coronavirus stress, optimism, social connectedness, and COVID-19 burnout. Females reported more coronavirus stress and burnout and less social connectedness. People confirmed with COVID-19 reported lower optimism. The results indicated that coronavirus stress did not only have a direct effect on increased COVID-19 burnout but also had an indirect effect on it through reduced optimism and social connectedness. These results are important given the shortage of intervention efforts targeting coronavirus stress. Future intervention efforts aimed at reducing coronavirus stress and related outcomes may benefit from simultaneously focusing on optimism and social connectedness.
\end{abstract}

Keywords Coronavirus stress $\cdot$ Optimism $\cdot$ Social connectedness $\cdot$ COVID-19 burnout $\cdot$ Healthcare staffs

The coronavirus disease 19 (COVID-19) pandemic has both eradicated and affected lives worldwide, leading to a new set of challenges across the globe. As of 12 April 2021, there have been 135,646,617 confirmed cases and 2,930,732 deaths of COVID-19 in the world while over 3,849,011 confirmed cases of COVID-19 with 33,939 deaths were reported across Turkey (World Health Organization, 2020). The pandemic had led to an excessive psychosocial impact on individuals, particularly those healthcare staffs working at the frontline of the pandemic (Ylldırm et al., 2021b). This unprecedented time has potential to exacerbate severity of mental health problems both during and after the pandemic (Doyumgaç et al., 2021; Tanhan, 2020). Previous study indicated the

Murat Yildırım

muratyildirim@agri.edu.tr; muratyildirimphd@gmail.com

1 Department of Psychology, Faculty of Science and Letters, Ağr1 İbrahim Çeçen University, Erzurum Yolu 4 Km 04100, Merkez, Ağrı, Turkey

2 Department of Neuroscience, Psychology and Behaviour, University of Leicester, Leicester, UK

3 Department of Child Development, Health College, Batman University, Batman, Turkey

4 Health Vocational School, Batman University, Batman, Turkey importance of determining the factors associated with poor mental health of healthcare staffs and the importance of timely interventions that help to protect their mental health in the face of adversity (Yildırım et al., 2020).

COVID-19 pandemic has caused considerable stress endangering the mental health and well-being of healthcare staffs. Studies showed that COVID-19 stress can induce mild to severe levels of psychosocial and mental health problems, such as depression, anxiety, post-traumatic stress, and loneliness (Arslan, 2020; Arslan \& Yildırım, 2021; Ceri \& Cicek, 2021), burnout among health care professionals (Y1ldirım \& Solmaz, 2020), physical isolation and loneliness (Tanhan et al., 2020), and adjustment problems (Arslan et al., 2021). However, evidence is limited regarding the impact of current pandemic on healthcare staff burnout derived from coronavirus stress, particularly underlying mechanism of both variables. Despite urgent needs highlighting the importance of protecting healthcare staff mental health during the COVID19 pandemic, only a single study, to the best of our knowledge, has focused on the mechanisms underlying between coronavirus stress and COVID-19 burnout.

Although there is evidence of the effect of coronavirus on general public mental health and well-being, little is known about the mechanism that may assist to uncover the association between coronavirus stress and burnout in healthcare 
staffs. Burnout is identified as a psychological syndrome derived from a long-lasting response to interpersonal stressors, mainly on the job (Maslach \& Leiter, 2016). Burnout is a complex and multidimensional phenomenon that comprises of emotional exhaustion, depersonalization, and reduced personal accomplishment (Maslach \& Jackson, 1981; Maslach \& Leiter, 2016). The emotional exhaustion is a state of feeling emotionally wearing out, loss of energy, debilitation, depletion, and fatigue in a consequence of accumulated stress resulted from one's personal or professional lives or a combination of two. The depersonalization refers to the development of negative attitudes toward clients, irritability, withdrawal, and loss of idealism. The sense of reduced personal accomplishment presents a reduced productivity or experience of poor capability, morale, and an inability to deal with stressors (De Oliveira et al., 2011; Maslach \& Leiter, 2016).

High rates of burnout and depressive symptoms (roughly $27.3 \%$ ) and significant positive relationship between them have been reported during COVID-19 pandemic in Saudi Arabia (Alkhamees et al., 2020). Using a Turkish general population, Y1ldirım and Solmaz (2020) highlighted the urgency of understanding the factors related to people experience of stress and burnout during the COVID-19 pandemic and understanding the key role of character strengths (e.g., resilience) that explain the relationship between coronavirus stress and burnout. They reported that resilience acted as mediator between coronavirus stress and burnout. Another study conducted during the COVID-19 pandemic on healthcare workers found that a high level of burnout was associated with greater depression, anxiety, stress, and worry related to COVID-19 (Talaee et al., 2020).

\section{Optimism and Social Connectedness as Mediator}

Optimism is a critical concept in positive psychology research and defined as an inclination to expect positive outcomes in one's life (Carver et al., 2010) and an overall positive outlook toward present and future life (Dember, 2001). An optimistic person typically has a positive expectation of the future, which in turn produces positive energy to the person, allowing then to cope with challenges effectively (Scheier \& Carver, 1992). Among healthcare staffs, optimism enhances their level of positive functioning, patients' satisfaction, and therapeutic outcomes. Optimistic healthcare staffs experience less pressure, use fewer maladaptive strategies, utilise more problem focused strategies, seek explicit social support, and hold more trust in people and organizations (Boldor et al., 2012). Optimism is an important concept and has many benefits to people including higher levels of physical health, subjective well-being, and success (Hao et al., 2016). Optimism leads to improvement of work-related performances among the healthcare staffs (Luthans et al., 2008). Optimism is a coping strategy that is an useful source in coping with stress and promoting well-being and mental health in the face of adversity (Genç \& Arslan, 2021; Reyes et al., 2020). Evidence from the context of COVID-19 supports the mediating role of optimism in the relationship between coronavirus stress and depression, anxiety, and somatization (Arslan et al., 2020). Higher optimism was also associated with less job stress and emotional exhaustion in healthcare workers (Özdemir \& Kerse, 2020). These results suggest that optimism is an important construct in terms of predicting and promoting mental health during disasters.

Social connectedness is defined as "an attribute of the self that reflects cognitions of enduring interpersonal closeness with the social world in toto" (Lee et al., 2001). Despite the potential loss of social connectedness as a primary contributor to medical staffs' burnout, it has not been receiving adequate attention in coping with burnout among members of healthcare teams (Southwick \& Southwick, 2020). Social connectedness is a vital factor to reduce burnout. According to Southwick and Southwick (2020), social connectedness is a fundamental human need that when lost results in burnout, and promotion of social connectedness plays a major role to enhance health and well-being of medical staffs. This is because, social connectedness facilitates a survival advantage via sharing of resources and facilitating safety in various ways while social exclusion, isolation, and rejection lead to psychosocial and physical challenges (Eisenberger, 2013). Previous research showed that a high level of social connectedness helps individuals to cope with anxiety and depression via increasing positive affect and decreasing negative affect (Taylor et al., 2020). Social connectedness also serves as a mediator between negative life experiences (e.g., maltreatment) and well-being outcomes including positive affect, negative affect, and satisfaction with life (Arslan, 2018). While social distancing as a measure of COVID-19 pandemic targets to reduce inperson contacts and prevent the spread of disease, it might increase risks of social isolation (Chen et al., 2020). Social disconnectedness has been related to negative physical and mental health outcomes such as symptoms of depression and anxiety (Santini et al., 2020). The role of social connectedness in protecting mental health occurred in various health crises including COVID-19 pandemic (Liotta et al., 2020). A high level of social connectedness during COVID-19 pandemic was related with reduced distress and fatigue (Nitschke et al., 2020). Therefore, social connectedness can play a protective or mitigative factor during a crisis impacting mental health of healthcare staffs.

\section{Present Study}

This study sought to examine the mediating role of optimism and social connectedness in the association between the 
coronavirus stress and COVID-19 burnout. Therefore, the findings obtained from this research were believed to contribute to the understanding of the association between the analysed variables as well as supporting mental health professionals to design and implement mental health intervention programs to protect mental health of healthcare staffs in difficult times. In the light of above-mentioned literature, we tested the following hypotheses: (i) coronavirus stress would significantly and negatively predict optimism and social connectedness and positively predict COVID-19 burnout, (ii) optimism and social connectedness would significantly and negatively predict COVID-19 burnout, and (iii) optimism and social connectedness would function as significant mediators in the association between coronavirus stress and COVID-19 burnout. The hypothesised structural model of the present research is illustrated in Fig. 1.

\section{Method}

\section{Participants}

Participants $(n=1046)$ were healthcare staffs who worked at different hospitals in Turkey. They ranged in age between 20 and $61(M=30.29, S D=7.80)$. Of those, $594(56.8 \%)$ participants were females and $452(43.2 \%)$ of them were males. Most of them $(51.5 \%, n=539)$ were single and nurses $(52 \%, n=544)$. Of the participants, $20.7 \%(n=216)$ of people reported that they were confirmed with COVID-19 while $48.5 \%(n=507)$ reported that their household members confirmed with COVID-19. Some participants $(15.9 \%, n=166)$ reported pre-existing chronic disease. A detailed description of participants characteristics is presented in Table 1 .

\section{Measures}

Coronavirus Stress Measure (CSM) developed by Arslan et al. (2020) includes five items. Each item is answered on a 5 -point Likert type scale ranging from $0=$ never to $4=$ very often. A sample item is "In the last month due to coronavirus, how often have you felt that you were unable to control the important things in your life?" Higher scores on the scale signify higher level of stress related to coronavirus. In this study, the Cronbach alpha coefficient for the CSM was 0.73 .

COVID-19 Burnout Scale (COVID-19-BS) developed by Yildirım and Solmaz (2020) consists of 10 items and each item is rated a 5 -point Likert type scale ranging from $1=$ never to $5=$ always. An example item is "When you think about COVID-19 overall, how often do you feel hopeless?". High scores indicate greater COVID-19 burnout. In this study, the Cronbach alpha coefficient for the COVID-19-BS was 0.94 .

Optimism-Pessimism Scale (OPS) constructed by Çalışkan and Uzunkol (2018) comprises of two dimensions (optimism - eight items and pessimism - eight items. Only optimism items were selected for this study. Each item is answered on a 5-point Likert type scale ranging between $1=$ never appropriate and $5=$ completely appropriate. A sample item is "I'm always optimistic about my future." Higher scores demonstrate higher optimism. In this study, the Cronbach alpha coefficient for the OPS was 0.91.

Social Connectedness Scale (SCS) developed by Lee and Robbins (1995) includes eight items. Each item is rated on a 6-

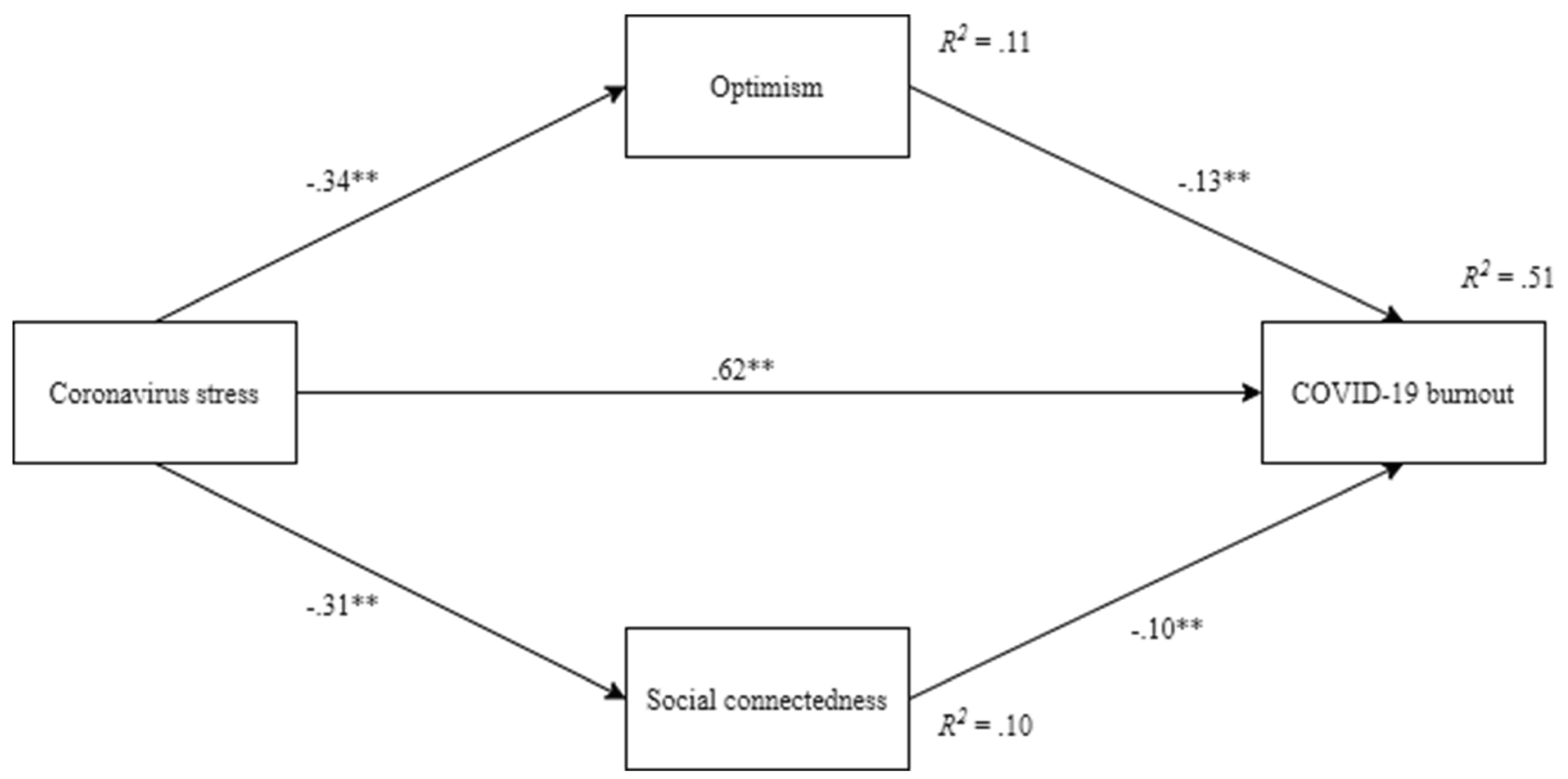

Fig. 1 Structural model depicting the associations between the variables. Note. ${ }^{* *} p<.001$ 
Table 1 Summary of sample characteristics

\begin{tabular}{llll}
\hline Group & Level & $\mathrm{n}$ & $\%$ \\
\hline Gender & Females & 594 & 56.8 \\
& Males & 452 & 43.2 \\
Relationship status & Single & 539 & 51.5 \\
& Married & 486 & 46.5 \\
& Widowed/divorced & 21 & 2.0 \\
Occupation & Doctor & 111 & 10.6 \\
& Nurse & 544 & 52.0 \\
Confirmed with COVID-19 & Healthcare-allied workers & 391 & 37.4 \\
& Yes & 216 & 20.7 \\
Household members confirmed with COVID-19 & No & 830 & 79.3 \\
& Yes & 507 & 48.5 \\
Pre-existing chronic disease & No & 539 & 51.5 \\
& Yes & 166 & 15.9 \\
& No & 880 & 84.1 \\
\hline
\end{tabular}

point Likert type scale ranging from $1=$ completely agree, $6=$ completely disagree. A sample item is "I feel so distant from people." High points indicate high social connectedness. The Turkish adaptation of the scale was done by Duru (2007). In this study, the Cronbach alpha coefficient for the COVID-19BS was 0.93 .

\section{Procedure}

The data for this cross-sectional study were collected through social networking sites with web survey between 15 November 2020 and 5 December 2020. The participants were given necessary information about the aim of the study. All participants provided written informed consent prior to involvement in this study. Participants who participated in the study were asked to complete an anonymous online survey, including survey measures and demographic information. No incentives were given to the participants. Participants were fully informed about the purpose of the study, their rights during and after the involvement in the study, and confidentiality of responses. Participants completed all measures in the same order. The present study was approved by and was conducted in accordance with the recommendations of an university institutional review board (Ethic Code: 2020/5-24).

\section{Data Analysis}

Descriptive statistics were performed on demographic factors to summarize the age, gender, relationship status, occupation, confirmed with COVID-19, household members confirmed with COVID-19 and history of pre-existing chronic disease in our sample. We estimated the mean and standard deviation for all scales, and then explored the nature of the relationships among the variables using bivariate correlations. Independent sample t-test was run to compare participants across the study variables.

A mediation analysis was carried out to examine the indirect effect of coronavirus stress on COVID-19 burnout through optimism and social connectedness. Based on recommendation of Hayes (2013) and MacKinnon et al. (2007), a bootstrapping procedure 10,000 resamples was run to estimate the $95 \%$ confidence intervals. Standardized regression estimate $(\beta)$ scores and squared-multiple correlations $\left(R^{2}\right)$ were calculated to interpret the results of the mediation analysis, with the effect criterion: $0.01-0.059=$ small, 0.06 - $0.139=$ moderate, and $\geq 0.14=$ large (Cohen, 1988). The parallel mediation analysis was computed using the PROCESS macro for SPSS, version 3.4 and the structure validity of the COVID-19-BS was run using the AMOS version 25.0 .

\section{Results}

\section{Structure Validity of COVID-19-BS}

Given that the COVID-19-BS has not been validated in healthcare context yet, we first begun by testing the factor structure of the scale with the present sample. To end that, we performed a confirmatory factor analysis (CFA) by using several data model fit statistics and their cut-off points as follows: the standardized root mean square residual (SRMR $\leq 0.05=$ good data-model fit and $\leq 0.08=$ adequate fit) and the root mean square error of approximation (RMSEA $\leq 0.05=$ good data-model fit, $\leq 0.08=$ adequate fit, and $\leq 0.10=$ Acceptable fit); Tucker-Lewis index and comparative fit index (TLI and CFI $\geq 0.95=$ good data-model fit and $\geq 0.90=$ adequate fit) (Hooper et al., 2008; Hu \& Bentler, 1999). The 
results of CFA showed that the measurement model for COVID-19-BS which composed of the 10 items loading to COVID-19 burnout latent construct, presented adequate-data model fit statistics $\left(X^{2}=476.45, d f=35, p<0.001, \mathrm{CFI}=\right.$ $0.95, \mathrm{TLI}=0.93, \mathrm{RMSEA}=0.10 \mathrm{SRMR}=0.035)$. The standardised factor loadings were between .62 and .89 . This suggests that the COVID-19-BS is an unidimensional scale that can be used in healthcare context.

\section{Comparison of Demographic Factors}

We computed independent sample t-test to compare gender and participants with history of COVID-19. The results of ttest indicated that females reported greater levels of coronavirus stress and COVID-19 burnout and a lower level of social connectedness than males. The results also showed that participants confirmed with COVID-19 reported a lower level of optimism that those who were not confirmed with COVID-19 (see Tables 2 and 3).

\section{Associations among Study Variables}

The assumption of normality was tested with skewness and kurtosis statistics. The findings indicated that skewness ranged from -0.17 to -0.44 , and kurtosis were between -0.09 and -0.54 , suggesting that all scales had relatively normal distribution. Pearson correlations were estimated among the study variables (see Table 4). Coronavirus stress was negatively correlated with optimism and social connectedness and positively correlated with COVID-19 burnout. Additionally, optimism was positively correlated with social connectedness

Table 2 Comparison of gender and participants with COVID-19 history

\begin{tabular}{lllllll}
\hline Variable & Gender & $\mathrm{N}$ & Mean & $\mathrm{SD}$ & $\mathrm{t}$ & $p$ \\
\hline Coronavirus stress & Female & 594 & 12.40 & 3.19 & 5.22 & 0.00 \\
& Male & 452 & 11.31 & 3.48 & & \\
Optimism & Female & 594 & 25.62 & 6.81 & -0.84 & 0.40 \\
& Male & 452 & 25.98 & 6.91 & & \\
Social connectedness & Female & 594 & 29.34 & 9.51 & -2.36 & 0.02 \\
& Male & 452 & 30.73 & 9.44 & & \\
COVID-19 burnout & Female & 594 & 35.05 & 9.07 & 7.71 & 0.00 \\
& Male & 452 & 30.51 & 9.91 & & \\
Confirmed with COVID-19 & & & & & \\
Coronavirus stress & Yes & 216 & 12.19 & 3.55 & 1.28 & 0.20 \\
& No & 830 & 11.86 & 3.31 & & \\
Optimism & Yes & 216 & 24.86 & 7.81 & -2.23 & 0.03 \\
Social connectedness & Yo & 830 & 26.02 & 6.56 & & \\
& No & 216 & 29.55 & 9.97 & -0.68 & 0.49 \\
COVID-19 burnout & Yes & 216 & 33.10 & 10.08 & 0.02 & 0.98 \\
& No & 830 & 33.09 & 9.61 & & \\
\hline
\end{tabular}

and negatively correlated with COVID-19 burnout. Lastly, social connectedness was negatively associated with COVID-19 burnout.

\section{Mediation Analysis}

Using the PROCESS macro with Model 4, a parallel mediation analysis was performed with a bootstrapping resampling procedure to examine the indirect effect of coronavirus stress on COVID-19 burnout through optimism and social connectedness (see Fig. 1). The results showed that coronavirus stress was a significant predictor of optimism $(\beta=-0.34$, $p<0.001)$, social connectedness $(\beta=-0.31, p<0.001)$, and COVID-19 burnout ( $\beta=0.62, p<0.001$ ). Coronavirus stress explained $11 \%$ of the variance in optimism and $10 \%$ of the variance in social connectedness. Additionally, the results indicated that coronavirus stress had indirect effects on COVID19 burnout through optimism $(\beta=-0.13, p<0.001)$ and social connectedness $(\beta=-0.10, p<0.001)$. Optimism and social connectedness partially mediated the effect of coronavirus stress on COVID-19 burnout. Coronavirus stress, optimism and social connectedness collectively accounted for $51 \%$ of the variance in COVID-19 burnout, as shown in Table 3. The indirect effects of coronavirus stress on COVID-19 burnout through optimism and social connectedness was significant. Standardized total and indirect effects with $95 \%$ biascorrected confidence interval relating to COVID-19 burnout are presented in Table 5 .

\section{Discussion}

The present study investigated the mediating role of optimism and social connectedness in the relationship between coronavirus stress and COVID-19 burnout among healthcare staffs. To the best of our knowledge, this is the first study to examine such a relationship in healthcare context, therefore significantly contributing to the field of healthcare staffs' mental health. Overall, the obtained results support the study hypotheses.

One important finding of this study is that the COVID-19BS yielded one-factor solution which had high standardised factor loadings with an excellent internal consistency reliability estimate. This suggests that the scale can be reliably used in health care context. This result is consistent with those studies previously reporting that the COVID-19-BS had an unidimensional factor solution in general public (Yıldırım \& Solmaz, 2020).

In this study, females experienced more challenges related to COVID-19 pandemic such as more stress and burnout and poor social connectedness. Those who confirmed with COVID-19 also had poor optimism then others. These findings are consistent with previous findings reported from the context of pandemic (Y1ldırım et al., 2021a). Correlational 
Table 3 Descriptive statistics and correlations

\begin{tabular}{lccccccccc}
\hline Variable & Mean & SD & Skew. & Kurt. & $\alpha$ & 1. & 2. & 3. & 4. \\
\hline 1. Coronavirus stress & 11.93 & 3.36 & -0.44 & 0.40 & .73 & - & $-.34^{* *}$ & $-.32^{* * *}$ & $.69^{* *}$ \\
2. Optimism & 25.78 & 6.85 & -0.23 & -0.25 & .91 & - & $.50^{* *}$ & $-.39^{* *}$ \\
3. Social connectedness & 29.94 & 9.50 & -0.17 & -0.09 & .93 & & - & $-.36^{* *}$ \\
4. COVID-19 burnout & 33.09 & 9.70 & -0.30 & -0.54 & .94 & & & - \\
\hline
\end{tabular}

$* * p<0.01$ results indicated that coronavirus stress had a significant relationship with optimism, social connectedness, and COVID-19 burnout. These results are consistent with earlier research that reported relationship between coronavirus stress and COVID19 burnout (Talaee et al., 2020; Yildırım \& Solmaz, 2020), coronavirus stress and optimism (Arslan et al., 2020; Arslan \& Yıldırım, 2021), coronavirus stress and social connectedness (Nitschke et al., 2020).

The most interesting result of this study is to demonstrate that optimism and social connectedness functioned as partial mediators of the association between coronavirus stress and COVID-19 burnout in healthcare staffs. That is, those with higher levels of coronavirus stress had tendency to experience less optimism and social connectedness which in turn contributed to an increase in their burnout related to COVID-19. This suggests that personal and social resources are great sources to mitigate the impact of pandemic related stressors on mental

Table 4 Unstandardized coefficients for the mediation model

\begin{tabular}{|c|c|c|c|c|c|}
\hline \multirow{3}{*}{$\begin{array}{l} \\
\text { Antecedent }\end{array}$} & & \multicolumn{4}{|c|}{ Consequent } \\
\hline & & \multicolumn{4}{|c|}{$M_{l}($ Optimism $)$} \\
\hline & & Coeff. & $S E$ & $t$ & $p$ \\
\hline$X$ (Coronavirus stress) & $a_{1}$ & -.69 & .06 & -11.64 & $<.001$ \\
\hline Constant & $i_{\mathrm{M} 1}$ & 34.01 & .74 & 46.27 & $<.001$ \\
\hline \multicolumn{6}{|l|}{$\begin{array}{l}R^{2}=.11 \\
F=135.40 ; p<.001\end{array}$} \\
\hline \multicolumn{6}{|l|}{$M_{2}$ (Social connectedness) } \\
\hline$X$ (Coronavirus stress) & $a_{2}$ & -.89 & .08 & -10.72 & $<.001$ \\
\hline Constant & $i_{\mathrm{M} 2}$ & 40.55 & 1.03 & 39.42 & $<.001$ \\
\hline \multicolumn{6}{|l|}{$\begin{array}{l}R^{2}=.10 \\
F=114.86 ; p<.001\end{array}$} \\
\hline \multicolumn{6}{|l|}{$Y$ (COVID-19 burnout) } \\
\hline$X$ (Coronavirus stress) & $c^{\prime}$ & 1.78 & .07 & 26.29 & $<.001$ \\
\hline$M_{l}($ Optimism $)$ & $b_{1}$ & -.18 & .04 & -5.03 & $<.001$ \\
\hline$M_{2}$ (Social connectedness) & $b_{2}$ & -.10 & .03 & -3.92 & $<.001$ \\
\hline Constant & $i_{\mathrm{y}}$ & 19.64 & 1.45 & 13.56 & $<.001$ \\
\hline $\begin{array}{l}R^{2}=.51 \\
F=362.33 ; p<.001\end{array}$ & & & & & \\
\hline
\end{tabular}

$S E$, standard error.; Coeff, unstandardized coefficient; $X$, independent variable; $M$, mediator variable; $Y$, dependent variable health outcomes. Optimism and social connectedness facilitate in dealing with stress in the face of adversity like the current pandemic. As such, these psychological resources may promote positive mental health and well-being of healthcare staffs. Although there is no available evidence regarding the simultaneous associations between the analysed variables, the findings from the mediation analysis are in accordance with those of similar previously published studies. Studies from the context of current pandemic showed that psychological strengths like optimism, resilience, and meaning in life mediated the association between coronavirus stress and COVID-19 burnout, well-being and mental health outcomes (Arslan et al., 2020; Arslan \& Y1ldırım, 2021; Özdemir \& Kerse, 2020; Yıldırım \& Solmaz, 2020). These results collectively suggest that optimism and social connectedness support the resilience ability of healthcare staffs to overcome and manage stress in difficult times.

\section{Implications and Limitations}

The present study contributes to the understanding of the relationship between coronavirus stress and COVID-19 burnout by showing that optimism and social connectedness partially account for their association. The findings of this study demonstrate the critical role of optimism and social connectedness in supporting healthcare staffs' mental health during the pandemic. Coronavirus stress impairs optimism and social connectedness which in turn increase COVID-19 burnout. As optimism and social connectedness were associated with reduced coronavirus stress and COVID-19 burnout, it is imperative that hospitals tailor COVID-19 training programs to improve the capacity of healthcare staffs to effectively cope with stressors and provide better care for patients. Due to the nature of COVID-19 pandemic which requires to maintain social distancing, this can be effectively facilitated using alternative platforms such as social media platforms, webinars, or other video technologies. Equipping healthcare staffs with adequate optimism and social connectedness is crucial to reduce the effect of coronavirus stress on burnout. For example, a virtual buddy system where a staff is paired with another staff can help build social connectedness during the pandemic crisis. With virtual buddy system, support can be provided to healthcare staffs to be more optimistic in the face of adversity. 
Table 5 Standardized indirect effects

\begin{tabular}{lllll}
\hline Path & Effect & SE & BootLLCI & BootULCI \\
\hline Total & .22 & .03 & .15 & .28 \\
Coronavirus stress->Optimism->COVID-19 burnout & .13 & .03 & .07 & .19 \\
Coronavirus stress->Social connectedness-> COVID-19 burnout & .09 & .03 & .04 & .15 \\
\hline
\end{tabular}

Number of bootstrap samples for percentile bootstrap confidence intervals: 10,000
As excessive coronavirus stress provokes COVID-19 burnout, which ultimately affects staffs' mental health and well-being, hospital administrators should prioritize healthcare staffs' mental and psychological health by focusing on optimism and social connectedness. Such a support may ultimately help to maintain psychological health and reduce stress and burnout among healthcare staffs.

The limitations of this study should be acknowledged. First, it is a cross-sectional study which restricts to monitor the longitudinal effect of coronavirus stress on burnout over time in the participants. Since data were collected using a cross-sectional design, causal relationships between the variables cannot be assured. Second, self-report measures were used to collect data. Participants may have been affected by the social desirability bias by overemphasizing responses to present themselves favourably. Thirdly, as many other internet surveys, the current study was not based on probability sampling. The survey questionnaires were distributed through social networking sites (e.g., WhatsApp). Participants were those people who had a smartphone with access to those social networking sites and agreed to take part in the survey. As such, this study may suffer from the limitation of selection bias (Bethlehem, 2010) which refers to the notion that it is completely up to participants to select themselves for the survey. Therefore, the results should be interpreted with caution when generalizing the conclusions of this study.

In conclusion, these results add to the burgeoning literature suggesting that psychosocial resources and strengths such as optimism and social connectedness are key elements in contributing to psychological health of healthcare staffs during pandemic. The present findings can be used to develop and implement effective and efficient preventions and interventions to deal with challenges of coronavirus stress. Thus, these results suggest the importance of hospital-based prevention and intervention services that improve the psychosocial resources and strengths at hospitals and foster the optimism and social connectedness which may contribute to cope with coronavirus stress and burnout.

Acknowledgements We thank to all participants who voluntarily contributed to this study.
Research Data Policy and Data Availability The datasets generated during and/or analysed during the current study are available from the corresponding author on reasonable request.

Author Contribution MY designed the study, analysed the data, and wrote the manuscript. İÇ and MEȘ disseminated the questionnaire. Authors approved the final version of the paper for the submission of it to the journal.

\section{Declarations}

Ethical Approval All procedures performed in studies involving human participants were in accordance with the ethical standards of the institutional and/or national research committee and with the 1964 Helsinki declaration and its later amendments or comparable ethical standards.

Conflict of Interest The authors declared no conflicts of interest with respect to the research, authorship, and/or publication of this article.

Informed Consent Consent was obtained from all participants included in the study.

\section{References}

Alkhamees, A. A., Assiri, H., Alharbi, H. Y., Nasser, A., \& Alkhamees, M. A. (2020). Burnout and depression among psychiatry residents during COVID-19 pandemic. Research Square, 1-17. https://doi. org/10.21203/rs.3.rs-41970/v2.

Arslan, G. (2018). Psychological maltreatment, social acceptance, social connectedness, and subjective wellbeing in adolescents. Journal of Happiness Studies, 19(4), 983-1001. https://doi.org/10.1007/ s10902-017-9856-z.

Arslan, G. (2020). Loneliness, college belongingness, subjective vitality, and psychological well-being during coronavirus pandemic: Preliminary development of the college belongingness questionnaire. Journal of Positive School Psychology. Retrieved from https://journalppw.com/index.php/JPPW/article/view/240

Arslan, G., \& Y1ldırı, M. (2021). Coronavirus stress, meaningful living, optimism, and depressive symptoms: A study of moderated mediation model. Australian Journal of Psychology, 1-12. https://doi.org/ 10.1080/00049530.2021.1882273.

Arslan, G., Yıldırım, M., Tanhan, A., Buluș, M., \& Allen, K. A. (2020). Coronavirus stress, optimism-pessimism, psychological inflexibility, and psychological health: Psychometric properties of the Coronavirus Stress Measure. International Journal of Mental Health and Addiction, 1-17. https://doi.org/10.1007/s11469-02000337-6.

Arslan, G., Yıldırım, M., \& Zangeneh, M. (2021). Coronavirus anxiety and psychological adjustment in college students: Exploring the role 
of college belongingness and social media addiction. International Journal of Mental Health and Addiction, 1-14. https://doi.org/10. 1007/s11469-020-00460-4.

Bethlehem, J. (2010). Selection bias in web surveys. International Statistical Review, 78(2), 161-188. https://doi.org/10.1111/j.17515823.2010.00112.x.

Boldor, N., Bar-Dayan, Y., Rosenbloom, T., Shemer, J., \& Bar-Dayan, Y. (2012). Optimism of health care workers during a disaster: A review of the literature. Emerging Health Threats Journal, 5(1), 7270. https://doi.org/10.3402/ehtj.v5i0.7270.

Çalışkan, H., \& Uzunkol, E. (2018). Ergenlerde iyimserlik-kötümserlik ölçeğinin geliştirilmesi: Geçerlilik ve güvenirlik çalışması. The Journal of Happiness \& Well-Being, 6(2), 78-95.

Carver, C. S., Scheier, M. F., \& Segerstrom, S. C. (2010). Optimism. Clinical Psychology Review, 30(7), 879-889. https://doi.org/10. 1016/j.cpr.2010.01.006.

Ceri, V., \& Cicek, I. (2021). Psychological well-being, depression and stress during COVID-19 pandemic in Turkey: A comparative study of healthcare professionals and non-healthcare professionals. Psychology, Health \& Medicine, 26(1), 85-97. https://doi.org/10. 1080/13548506.2020.1859566.

Chen, A. T., Ge, S., Cho, S., Teng, A. K., Chu, F., Demiris, G., \& Zaslavsky, O. (2020). Reactions to COVID-19, information and technology use, and social connectedness among older adults with pre-frailty and frailty. Geriatric Nursing, 42, 1-8. https://doi.org/10. 1016/j.gerinurse.2020.08.001.

Cohen, J. (1988). Statistical power analysis for the behavioral sciences. Academic press, 2nd ed, Lawrence Erlbaum.

De Oliveira, G. S., Ahmad, S., Stock, M. C., Harter, R. L., Almeida, M. D., Fitzgerald, P. C., \& McCarthy, R. J. (2011). High incidence of burnout in academic chairpersons of anaesthesiology: Should we be taking better care of our leaders? The Journal of the American Society of Anaesthesiologists, 114(1), 181-193. https://doi.org/10. 1097/ALN.0b013e318201cf6c.

Dember, W. N. (2001). The optimism-pessimism instrument: Personal and social correlates. In C. E. Chang (Ed.), Optimism and pessimism: Implications for theory, research, and practice (pp. 281299). American Psychological Association. https://doi.org/10. 1037/10385-013.

Doyumgaç, I., Tanhan, A., \& Kiymaz, M. S. (2021). Understanding the Most important facilitators and barriers for online education during COVID-19 through online Photovoice methodology. International Journal of Higher Education, 10(1), 166-190. https://doi.org/10. 5430/ijhe.v10n1p166.

Duru, E. (2007). The adaption of social connectedness scale Turkish culture. Eurasian Journal of Educational Research, 26, 85-94.

Eisenberger, N. I. (2013). An empirical review of the neural underpinnings of receiving and giving social support: Implications for health. Psychosomatic Medicine, 75(6), 545-556. https://doi.org/10.1097/ PSY.0b013e31829de2e7.

Genç, E., \& Arslan, G. (2021). Optimism and dispositional hope to promote college students' subjective well-being in the context of the COVID-19 pandemic. Journal of Positive School Psychology. Retrieved from https://journalppw.com/index.php/JPPW/article/ view/255

Hao, Y. N., Song, B. D., Wang, Y., Zhang, Q., \& Lang, Y. (2016). The positive bias of dispositional optimism and the evidence of neurophysiology research. Advances in Psychological Science, 24, 946957. https://doi.org/10.3724/SP.J.1042.2016.00946.

Hayes, A. F. (2013). Introduction to mediation, moderation, and conditional process analysis: A regression-based approach. Guilford Press.

Hooper, D., Coughlan, J., \& Mullen, M. R. (2008). Structural equation modelling: Guidelines for determining model fit. The Electronic Journal of Business Research Methods, 6(1), 53-60. https://doi. org/10.1080/10705519909540118.
Hu, L. T., \& Bentler, P. M. (1999). Cutoff criteria for fit indexes in covariance structure analysis: Conventional criteria versus new alternatives. Structural Equation Modeling: A Multidisciplinary Journal, 6(1), 1-55. https://doi.org/10.1080/10705519909540118.

Lee, R., \& Robbins, S. B. (1995). Measuring belongingness: The social connectedness and social assurance scales. Journal of Counselling Psychology, 42, 232-241. https://doi.org/10.1037/0022-0167.42.2. 232.

Lee, R. M., Draper, M., \& Lee, S. (2001). Social connectedness, dysfunctional interpersonal behaviors, and psychological distress: Testing a mediator model. Journal of Counseling Psychology, 48(3), 310 318. https://doi.org/10.1037/0022-0167.48.3.310.

Liotta, G., Marazzi, M. C., Orlando, S., \& Palombi, L. (2020). Is social connectedness a risk factor for the spreading of COVID-19 among older adults? The Italian paradox. PLoS One, 15(5), e0233329. https://doi.org/10.1371/journal.pone.0233329.

Luthans, K. W., Lebsack, S. A., \& Lebsack, R. R. (2008). Positivity in healthcare: Relation of optimism to performance. Journal of Health Organization and Management, 22, 178-188. https://doi.org/10. 1108/14777260810876330.

MacKinnon, D. P., Fairchild, A. J., \& Fritz, M. S. (2007). Mediation analysis. Annual Review of Psychology, 58, 593-614. https://doi. org/10.1146/annurev.psych.58.110405.085542.

Maslach, C., \& Jackson, S. E. (1981). The measurement of experienced burnout. Journal of Organizational Behavior, 2(2), 99-113. https:// doi.org/10.1002/job.4030020205.

Maslach, C., \& Leiter, M. P. (2016). Understanding the burnout experience: Recent research and its implications for psychiatry. World Psychiatry: Official Journal of the World Psychiatric Association (WPA), 15(2), 103-111. https://doi.org/10.1002/wps.20311.

Nitschke, J. P., Forbes, P. A., Ali, N., Cutler, J., Apps, M. A., Lockwood, P. L., \& Lamm, C. (2020). Resilience during uncertainty? Greater social connectedness during COVID-19 lockdown is associated with reduced distress and fatigue. British Journal of Health Psychology, 1-17. https://doi.org/10.1111/bjhp.12485.

Özdemir, Ș., \& Kerse, G. (2020). The effects of COVID 19 on health care workers: Analysing of the interaction between optimism, job stress and emotional exhaustion. International and Multidisciplinary Journal of Social Sciences, 9(2), 178-201. https://doi.org/10. 17583/rimcis.2020.5849.

Reyes, M. E., Gabrielle O. Dillague, S. ., Fuentes, M. I. A., Malicsi, C. A. R., Manalo, D. C. F., Melgarejo, J. M. T., \& Cayubit, R. F. O. (2020). Self-esteem and optimism as predictors of resilience among selected Filipino active-duty military personnel in military camps. Journal of Positive School Psychology, 4(1), 15-25.

Santini, Z. I., Jose, P. E., Cornwell, E. Y., Koyanagi, A., Nielsen, L., Hinrichsen, C., et al. (2020). Social disconnectedness, perceived isolation, and symptoms of depression and anxiety among older Americans (NSHAP): A longitudinal mediation analysis. The Lancet Public Health, 5(1), e62-e70. https://doi.org/10.1016/ S2468-2667(19)30230-0.

Scheier, M. F., \& Carver, C. S. (1992). Effects of optimism on psychological and physical well-being: Theoretical overview and empirical update. Cognitive Therapy and Research, 16, 201-228. https://doi. org/10.1007/BF01173489.

Southwick, S. M., \& Southwick, F. S. (2020). The loss of social connectedness as a major contributor to physician burnout: Applying organizational and teamwork principles for prevention and recovery. JAMA Psychiatry, 77(5), 449-450. https://doi.org/10.1001/ jamapsychiatry.2019.4800.

Talaee, N., Varahram, M., Jamaati, H., Salimi, A., Attarchi, M., Kazempour Dizaji, M., et al. (2020). Stress and burnout in health care workers during COVID-19 pandemic: Validation of a questionnaire. Journal of Public Health, 1-6. https://doi.org/10.1007/ s10389-020-01313-z. 
Tanhan, A. (2020). COVID-19 sürecinde online seslifoto (OSF) yöntemiyle biyopsikososyal manevi ve ekonomik meseleleri ve genel iyi oluș düzeyini ele almak: OSF'nin Türkçeye uyarlanması. [Utilizing online photovoice (OPV) methodology to address biopsychosocial spiritual economic issues and wellbeing during COVID-19: Adapting OPV to Turkish.]. Turkish Studies, 15(4), 1029-1086. https://doi.org/10.7827/TurkishStudies.44451.

Tanhan, A., Yavuz, K. F., Young, J. S., Nalbant, A., Arslan, G., Yıldırım, M. ... Çiçek, İ. (2020). A proposed framework based on literature review of online contextual mental health services to enhance wellbeing and address psychopathology during covid-19. Electronic Journal of General Medicine, 17(6). https://doi.org/10. 29333/ejgm/8316

Taylor, C. T., Pearlstein, S. L., Kakaria, S., Lyubomirsky, S., \& Stein, M. B. (2020). Enhancing social connectedness in anxiety and depression through amplification of positivity: Preliminary treatment outcomes and process of change. Cognitive Therapy and Research, 44(4), 788-800. https://doi.org/10.1007/s10608-020-10102-7.

World Health Organization. (2020). WHO Coronavirus Disease (COVID-19) dashboard. https://covid19.who.int
Yıldırım, M., Arslan, G., \& Özaslan, A. (2020). Perceived risk and mental health problems among healthcare professionals during COVID-19 pandemic: Exploring the mediating effects of resilience and coronavirus fear. International Journal of Mental Health and Addiction, 1-11. https://doi.org/10.1007/s11469-020-00424-8.

Yıldırım, M., Geçer, E., \& Akgül, Ö. (2021a). The impacts of vulnerability, perceived risk, and fear on preventive behaviours against COVID-19. Psychology, Health \& Medicine, 26(1), 35-43.

Yıldırım, M., Özaslan, A., \& Arslan, G. (2021b). Perceived risk and parental coronavirus anxiety in healthcare workers: A moderated mediation role of coronavirus fear and mental well-being. Psychology, Health \& Medicine, 1-12. https://doi.org/10.1080/ 13548506.2021.1871771.

Yıldırım, M., \& Solmaz, F. (2020). COVID-19 burnout, COVID-19 stress and resilience: Initial psychometric properties of COVID-19 burnout scale, Death Studies, 1-10. https://doi.org/10.1080/ 07481187.2020 .1818885

Publisher's Note Springer Nature remains neutral with regard to jurisdictional claims in published maps and institutional affiliations. 